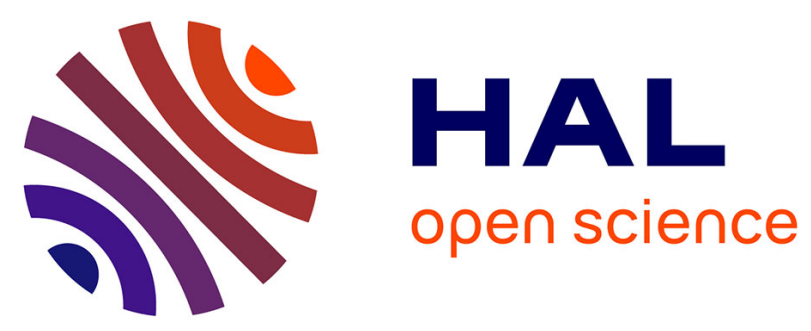

\title{
Numerical determination of the tensile response and the dissipated fracture energy of concrete: role of the meso-structure and influence of the loading rate
}

Fabrice Gatuingt, Léonardo Snozzi, Jean-François Molinari

\section{- To cite this version:}

Fabrice Gatuingt, Léonardo Snozzi, Jean-François Molinari. Numerical determination of the tensile response and the dissipated fracture energy of concrete: role of the meso-structure and influence of the loading rate. International Journal for Numerical and Analytical Methods in Geomechanics, 2013, 37, pp.3112-3130. 10.1002/nag.2181 . hal-00994253

\section{HAL Id: hal-00994253 \\ https://hal.science/hal-00994253}

Submitted on 21 May 2014

HAL is a multi-disciplinary open access archive for the deposit and dissemination of scientific research documents, whether they are published or not. The documents may come from teaching and research institutions in France or abroad, or from public or private research centers.
L'archive ouverte pluridisciplinaire HAL, est destinée au dépôt et à la diffusion de documents scientifiques de niveau recherche, publiés ou non, émanant des établissements d'enseignement et de recherche français ou étrangers, des laboratoires publics ou privés. 


\title{
Numerical determination of the tensile response and the dissipated fracture energy of concrete: role of the meso-structure and influence of the loading rate
}

\author{
F. Gatuingt*, L. SnOzzi** And J.F. Molinari** \\ *LMT-Cachan (ENS Cachan/CNRS/Université Paris 6/PRES UniverSud Paris), France \\ **LSMS, School of Architecture, Civil and Environmental Engineering (ENAC), EPFL, Switzerland
}

\begin{abstract}
At the mesoscopic scale concrete can be considered as a mix of coarse aggregates with a mortar paste matrix. In this paper we investigate numerically the influence of aggregates arrangements and loading rate on the tensile response of concrete. Each coarse aggregate is assumed to be circular with six different radiuses following the aggregates size distribution of real gravel. Rateindependent cohesive elements are used to model failure within the mesostructure. Our results show that the spatial distribution of heterogeneities does not influence the peak strength, while it changes the post-peak macroscopic response. This implies that our specimen size is large enough for strength computation but that larger mesostructures should be considered to obtain fully reliable toughness predictions. While, the cohesive approach is able to capture the transition from one macro-crack in quasi-static to multiple micro-cracks in fast dynamics, which increases the dissipated fracture energy, our results suggest that the full extent of the high-rate strengthening of concrete observed experimentally for loading rates greater than $\dot{\varepsilon}=1 / \mathrm{s}$ cannot be captured with rate independent constitutive laws.
\end{abstract}

\section{Introduction}

Reinforced concrete is one of the main materials used in constructions. Industrial or civil structures could be subjected to dynamic loads and these loads have to be taken into account in the design process. For example, structures that involve public safety have to be designed to resist not only to the static loading but also to the dynamic loading produced by extreme conditions such as earthquakes, explosions or accidental collisions. To achieve the design and analyses of these structures, it is important to investigate the dynamic mechanical response of concrete. Several macroscopic models for concrete have been developed [1, 2, 3, 4, 5, 6, 7, 8, 9, 10,11] to perform non-linear numerical analysis of such problems. In these models a rate effect in tension has often been introduced to represent the experimental data for loading strain rates exceeding $1 / \mathrm{s}[12,13]$. Indeed, it is well known that for loading rates ranging from static $\left(10^{-4} / \mathrm{s}\right)$ to intermediate $\left(10^{-1}-0 / \mathrm{s}\right)$, a moderate rate effect in tensile strength is observed. Beyond a loading strain rate of $1 / \mathrm{s}$ a very steep strength increase occurs.

Figure 1 shows a set of static, Split Hopkinson Bar (SHB) and modified SHB tests. The derived data on strength and fracture energy of theses tests are summarized in Table 1. These experimental 


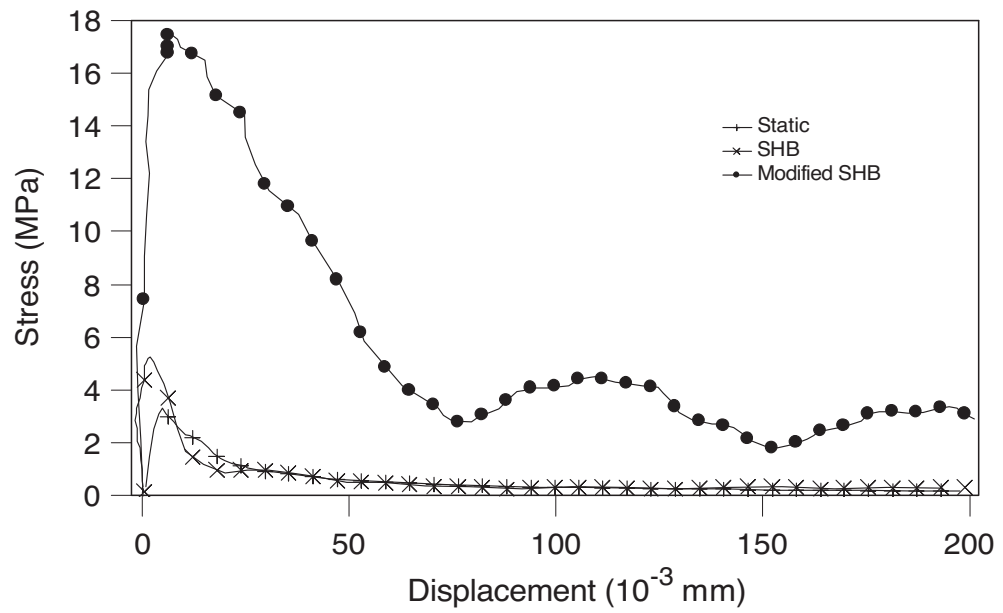

Figure 1: Experimental stress-displacement curves for static, SHB and Modified SHB tests (from [14]).

data show a rate effect on strength, and on the dissipated fracture energy, in the high loading rate regime. Table 1 also shows that for the higher loading velocity the dynamic increase factor is more important for the dissipated fracture energy than for the tensile strength. In addition, some authors have shown experimentally that the deformation capability of concrete under uniaxial tensile loading increases due to a rate effect $[15,16,17]$. As previously mentioned, it is usual to introduce in numerical models this dynamic increase factor directly in the macroscopic behaviour as shown in Figure 2. This has to be done with care as it is not clear how important the dissipation at the structural level is. Indeed, the increase of the fracture energy with the strain rate may be caused, in the experiments, by a structural effect (at the concrete sample level) instead of a material one's [18, 19].

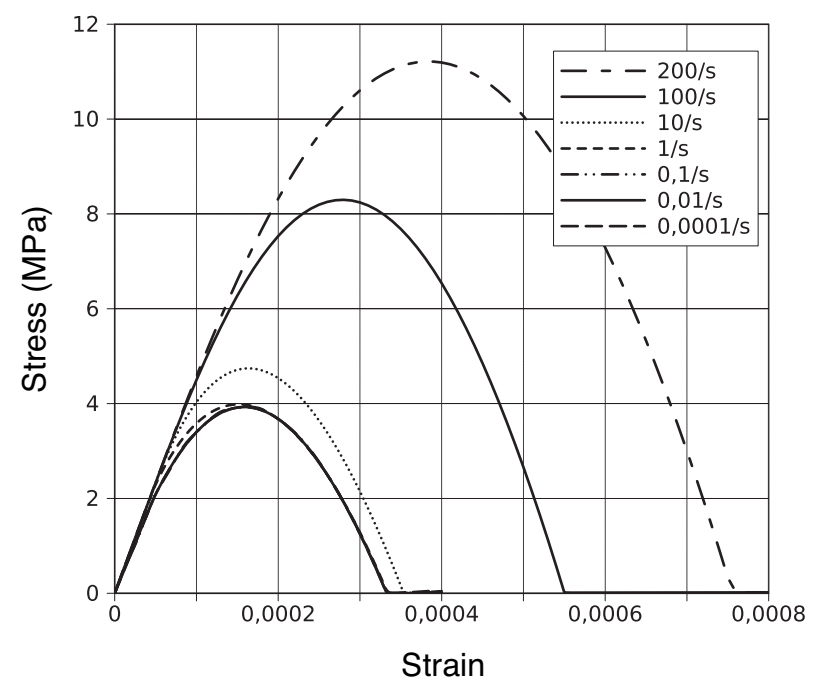

Figure 2: Uniaxial tension response for different loading rates of a classical visco-damage model (from $[20])$.

Multiple cracking and micro-inertia effects in the fracture process zone are thought as the main 
Table 1: Strength, fracture energy and dynamic/static ratio for concrete at different loading rates (from [14])

\begin{tabular}{c|c|c|c|c|c|} 
& $\begin{array}{c}\text { Load Rate } \\
\dot{\sigma}(G P a / s)\end{array}$ & $\begin{array}{c}\text { Tens. Strength } \\
f_{t}(M P a)\end{array}$ & $\begin{array}{c}\text { Fract. Energy } \\
G_{f}(\mathrm{~N} / \mathrm{m})\end{array}$ & $f_{t(\text { dyn })} / f_{t(\text { stat })}$ & $G_{f(\text { dyn })} / G_{f(\text { stat })}$ \\
\hline Static & $10^{-4}$ & 3.3 & 120 & 1 & 1 \\
\hline SHB & 39 & 5.58 & 120 & 1.7 & 1 \\
\hline Mod. SHB & 1685 & 17. & 1505 & 5.2 & 12.5 \\
\hline
\end{tabular}

factors for the rate dependency of concrete in the high dynamic regime. However, the influence of the internal microstructure of concrete and the mechanisms that lead to different crack patterns when varying the loading rate, remain open questions. In order to give some answers to these questions, concrete has to be considered as a heterogeneous material where the nature of the heterogeneity depends essentially on the scale of observation. If one takes the scale of sand's grain, concrete can be considered as a biphasic material made of aggregates of different sizes randomly distributed in a mortar matrix. Thus, the failure of a concrete sample in tension is related to processes that take place at the so-called mesoscale. In order to investigate the role of the meso-structure on the dynamic tensile response of concrete, one can use a numerical approach. This is achieved in this paper using a 2D finite element mesoscopic description of concrete (aggregates + matrix) with cohesive capability. This method has proven its efficiency on numerical simulations of fracture of brittle materials [21] and has been extended to concrete like materials [22].

This paper extends the work conducted by Snozzi et al. [22]. In the first section, we propose a more realistic description of the aggregates heterogeneities in a concrete. We generate different meshes based on five meso-structure descriptions of a concrete mix. In section 3, we describe the numerical tensile tests and investigate the mesh objectivity of the observed response. The effect of the stiffness of the inclusions (an additional complement to [22]) on the macroscopic tensile response is also discussed. In sections 4 and 5, the main aspects of this work are described. These are the study of the influence of the meso-structure on the tensile strain-stress curve and on the dynamic increase factors for the tensile strength and dissipated fracture energy.

\section{Meso-scale model}

The concrete constitutive behavior can be formulated either at the macro-scale or at the meso-scale. At the macro scale, the ingredients that characterize concrete's heterogeneity are not represented and one considers it as a homogeneous material. Nevertheless, it is a material whose heterogeneities (aggregates) can have sizes of the order of tens of millimeters, which influences fracture properties (the crack path is for instance clearly dependent on these heterogeneities). The approach used in this paper therefore considers concrete as a bi-phasic material: aggregates in a mortar paste, which is commonly called a meso-scale approach (as proposed in [23]). It allows an explicit representation of some concrete components, which enables reducing the number of model parameters, and a description of the interactions between matrix and inclusions. In the literature one can find several meso-scale models for concrete. They can be divided in two main computational classes. A first family is represented by lattice models (for instance [24, 25]), where the continuum is replaced by a system of discrete particles and the mechanical properties of the lattice beams aim to represent the concrete 
meso-structure $[26,27,28]$. The second class resorts to the finite-element approach, in which concrete is usually represented as a biphasic material, made of a mixture of aggregates embedded in a matrix phase with an interfacial transition zone (ITZ) between them [29, 30, 31, 32, 33, 22].

From those works it results that the meso-scale level of material observation is suitable to capture the main characteristics of the overall mechanical behavior of concrete: micro-cracking, fracture initiation and propagation, coalescence and localization. Moreover the constitutive equations might be relaxed when comparing with a macro-scale formulation and thus the number of parameters may be reduced.

In our model, the aggregates, the mortar and the interfacial transition zone (ITZ) will be represented as separate phases with different material properties. In order to study the specific effect of the meso-structure on the dynamic tensile response, no random fields have been introduced on the properties. A finite element approach with cohesive capability is then used to simulate the cracks opening and propagation.

\subsection{Meso-structure modelisation}

The macroscopic response of a heterogeneous material at the mesoscopic scale depends not only on the properties of the different phases but also on their geometric distribution. The aim of this paper is to see the influence of the heterogeneities on the mechanical response in tension. We have chosen constant mechanical properties and focus only on the spatial distribution of the heterogeneities.

Real concrete is based on randomly distributed aggregates in a cement paste matrix. Figure 3a shows particle size distributions for real sand and gravel used in a real concrete. These were obtained by a sieving method [34]. The aggregates called sand can be included either in the heterogeneities or in the cement paste depending on the fineness of the aggregates description in the meso-scale model. In our description, we chose to describe explicitly only the aggregates with a diameter larger than $4 \mathrm{~mm}$ and smaller than $25 \mathrm{~mm}$ with six classes to capture roughly the aggregates size distribution (see Figure 3b). The smallest aggregates are then taken into account in the homogeneous matrix of mortar. The size of the generated specimens is $100 \times 100 \mathrm{~mm}^{2}$. As in [35], knowing the aggregate size distribution, the number of perfect circular (in 2D) aggregates of each class can be calculated. To avoid an artificial increase of the volume matrix due to the boundary effect, the heterogeneities are placed in a larger sample with a final cut of all parts outside of the concrete specimen. Figure 4 shows five images of the meso-structures obtained using this method with the same aggregate size distribution of Figure 3b.

A 2D finite element mesh is then generated from the meso-structure images using the PPM2OOF [36] public domain software created at the National Institute of Standards and Technology (NIST). This software superimposes a mesh on any image. The simplest meshing algorithm tries to divide each image pixel into two triangular elements. In our approach, we resort to an adaptive meshing algorithm available in PPM2OOF. In this case, the mesh that is created represents the user's compromise between the number of elements and the homogeneity of each element with respect to its underlying pixel properties and the production of equilateral triangular elements.

Figure 5 shows a zoom on four different meshes obtained with the same image of the first mesostructure (Meso 1) of Figure 4. In mesh A, the average size of the elements is $1 \mathrm{~mm}$ (20000 elements), while in the mesh $\mathrm{B}$ the size is $0.5 \mathrm{~mm}$ (80000 elements) and in mesh $\mathrm{C}$ we have 180000 elements of approximately $0.3 \mathrm{~mm}$. A fourth, very fine mesh (thereafter called D), has also been generated with 320000 elements $(0.25 \mathrm{~mm})$ in order to study the convergence of the numerical results. One can observe that the definition of the contour of the aggregates and the real surface of paste is better 

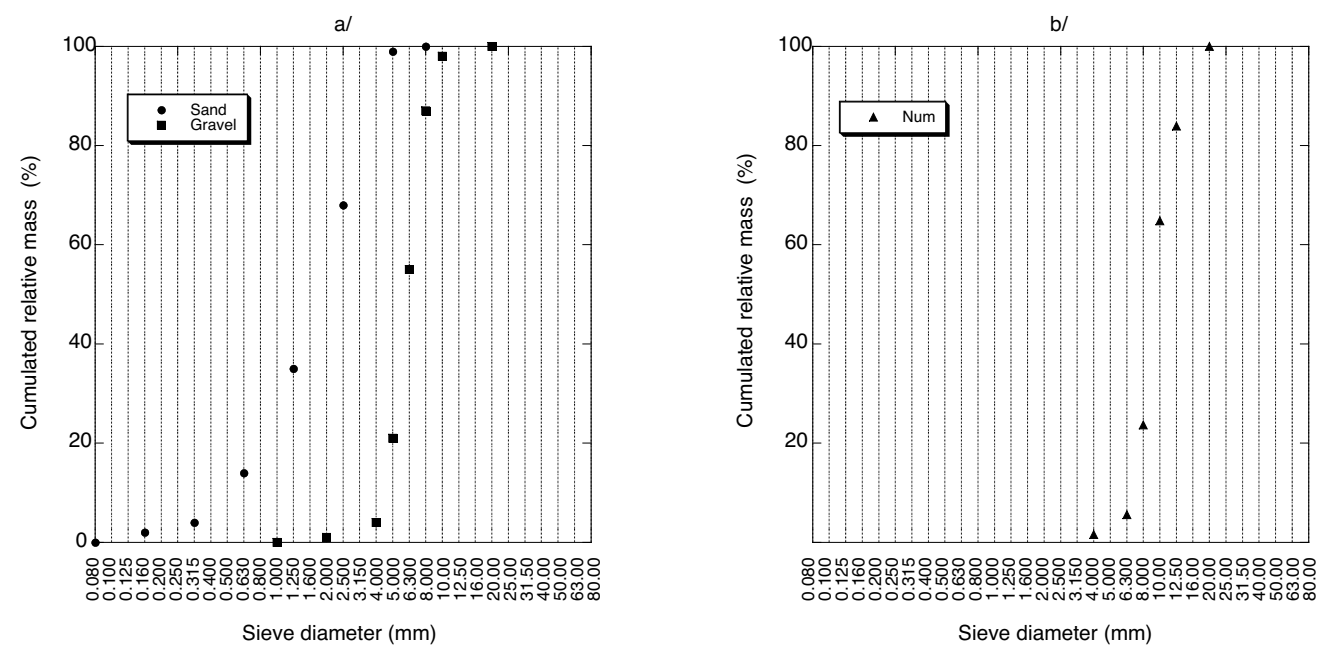

Figure 3: Aggregates size distribution according to EN 993-1 [34]: a/ Real sand and gravel, b/ Numerical (mostly gravel)

when the size of the mesh decreases. To illustrate this point, in the proposed zoom, one can see that the mortar in between two grains can disappear for the coarse meshes while it is well represented with the finer one.

Notice that this mesh generation is possible since the cohesive element methodology here does not require an a priori definition of the possible fracture planes [37, 29, 30, 38, 33, 32].

\subsection{The cohesive element method}

The cohesive element method allows us to model dynamic crack propagation and damage in a brittle material like concrete. The fracture process is described by the cohesive approach (introduced by Dugdale [39] and Barenblat [40] in the 1960s) as a separation process occurring at the crack tip in a small region of material called cohesive zone. This can be introduced into a standard finite element environment using interface elements with null thickness and with a fracture-based constitutive law. We assume that the bulk material outside the cohesive zone remains elastic. In our case the crack path is not known a priori and all lines in the mesh are considered as a potential crack path. During the simulation, the stress at the interface between two adjacent continuum elements is computed and compared to the fracture criterion at the end of every time step. The interfacial stress, $\sigma$, is calculated averaging stresses of the adjacent Gauss points of the two continuum elements. If the inter-element stress exceeds the critical stress value, the nodes located at the inter-element boundary are doubled, the two elements are topologically disconnected and a cohesive element is inserted (see Figure 6). After the nodal disconnection, the interfacial stress starts being controlled by the traction separation law implemented in the cohesive element (Figure 7).

The coupling of the above mentioned fracture criterion together with an initially rigid cohesive law allows capturing the initiation of new cracks without an a priori definition of the possible cracks. Nevertheless, the cracks are constrained to propagate following the inter-element boundaries and the fineness of the mesh can affect it. The law we use is the linear irreversible softening law proposed by Camacho and Ortiz [38]. The authors hypothesize the existence of a free potential energy $\Phi$, which depends on one effective scalar displacement which has the following form: 


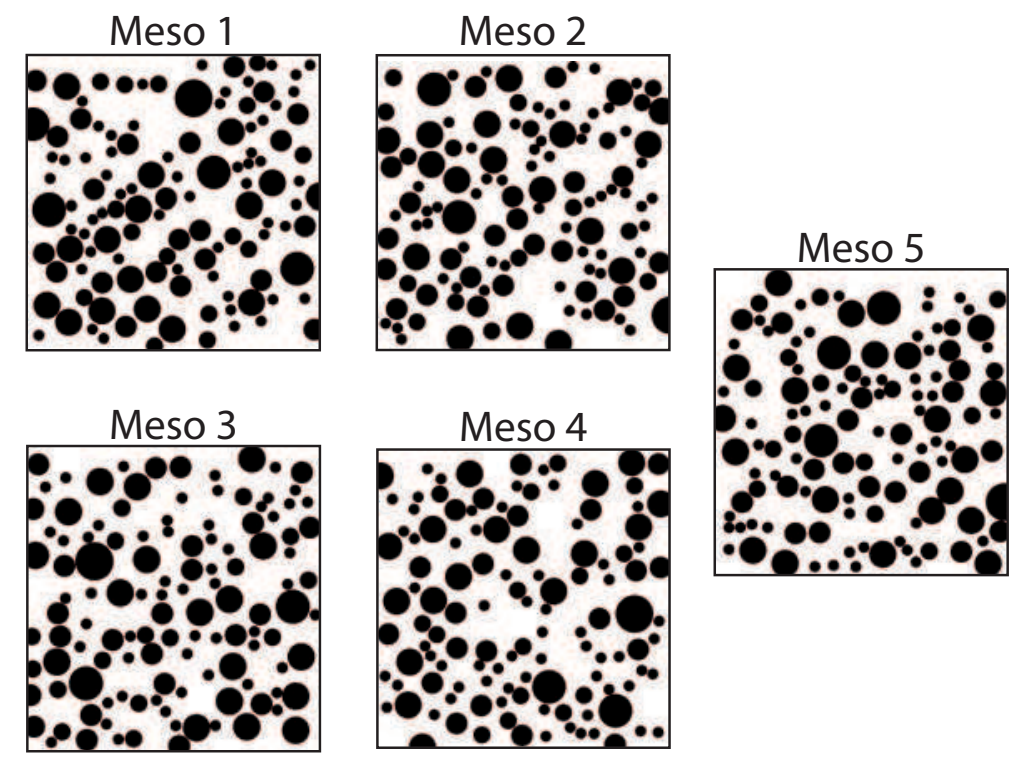

Figure 4: Different images of the meso-structures generated with the same aggregates size distribution.

$$
\delta=\sqrt{\Delta_{n}^{2}+\beta^{2} \Delta_{s}^{2}}
$$

where $\vec{\Delta}=\left(\Delta_{n}, \Delta_{s}\right)$ is the relative displacement vector and the parameter $\beta$ accounts for the coupling between normal and tangential displacements. The value of $\beta$ has to be estimated (e.g. by correlating experimental results with numerical simulations [41]) but it has been shown by [22] that the peak strength is only slightly affected by $\beta$ for a tensile loading. One will keep its value equal to one in this study.

The differentiation of the free potential energy with respect to the opening displacement leads to the cohesive tractions law:

$$
\vec{t}=\frac{\partial \Phi}{\partial \vec{\Delta}}=\frac{t}{\delta}\left(\Delta_{n} \vec{n}+\beta^{2} \Delta_{s} \vec{s}\right)
$$

where $t$ represents an effective cohesive traction. This traction in case of crack opening is given by:

$$
t=f_{c t}\left(1-\frac{\delta}{\delta_{c}}\right) \quad \text { for } \quad \delta=\delta_{\max } \quad \text { and } \quad \dot{\delta}>0
$$

Where $f_{c t}$ represents the local material strength and $\delta_{c}$ represents the effective relative displacement beyond which complete decohesion occurs. Whereas for crack closure or reopening ( $\delta$ smaller than $\left.\delta_{\max }\right)$ the functional form is assumed to have the form:

$$
t=\frac{\delta}{\delta_{\max }} t_{\max } \quad \text { for } \quad \delta<\delta_{\max }
$$

where $t_{\max }$ is the value of the effective traction when $\delta$ is equal to $\delta_{\max }$, in which is stored the maximal effective opening displacement attained up to the moment. Moreover $\delta_{\max }$ also accounts for the irreversibility of the law allowing successive loading, unloading and reloading. The evolution of the linear decreasing law is graphically shown in Figure 7. Note that the definition of $f_{c t}$ and $\delta_{c}$ 
A

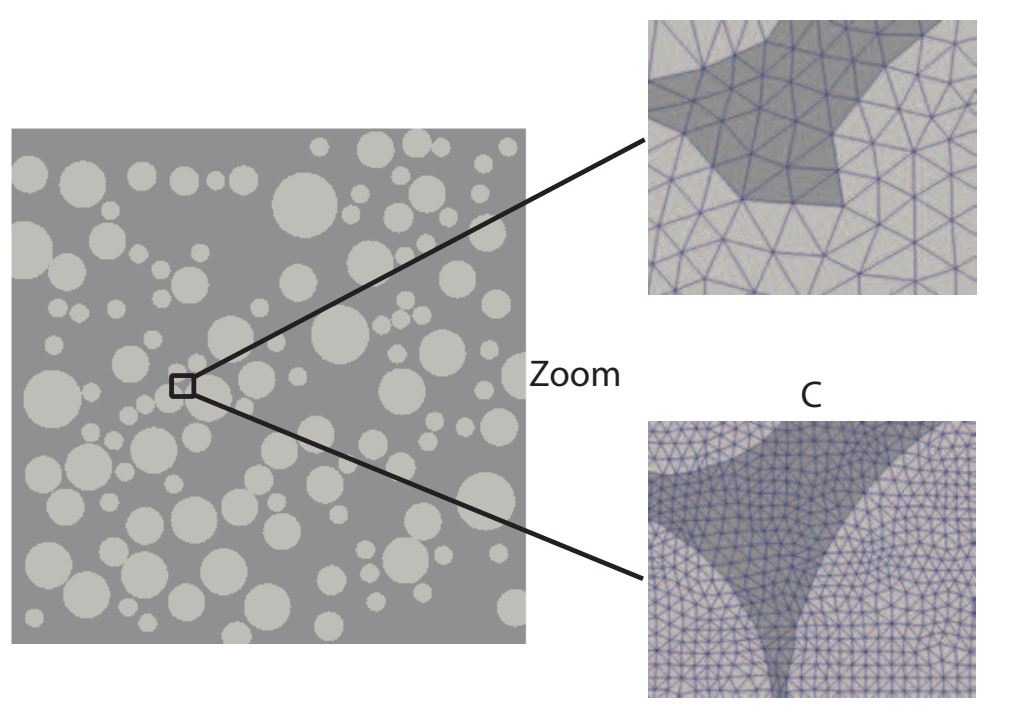

B
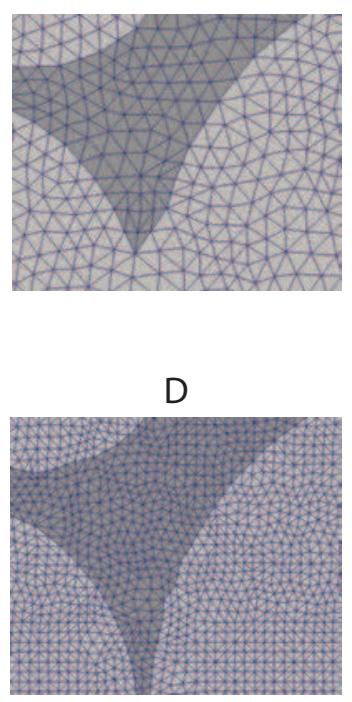

Figure 5: Different mesh sizes generated with PPM2OOF on the same meso-structure.
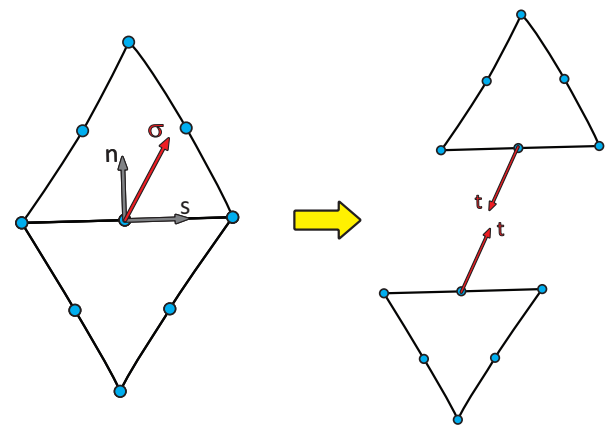

Figure 6: Schematic of the nodal disconnection between two continuum elements in which the interfacial stress has exceeded the critical stress

implicitly establishes the existence of an effective fracture energy $G_{c}$, which corresponds to the area under the curve of Figure 7:

$$
G_{c}=\frac{1}{2} f_{c t} \delta_{c}
$$

Partially damaged cohesive elements have dissipated an energy $W<G_{c}$. As the present work is focused on tensile uniaxial loading, the fracture energy of the different phases of our concrete is identified to the experimental one for Mode I, i.e. $G_{c}=G_{c}^{I}$.

\section{Numerical simulation of direct tensile test in dynamics}

\subsection{Initial and boundary conditions}

The aim of the present study is to analyze the dynamic tensile response of a concrete specimen (2D plane strain). The specimen is loaded under displacement control with an imposed strain rate $\dot{\varepsilon}$, all 


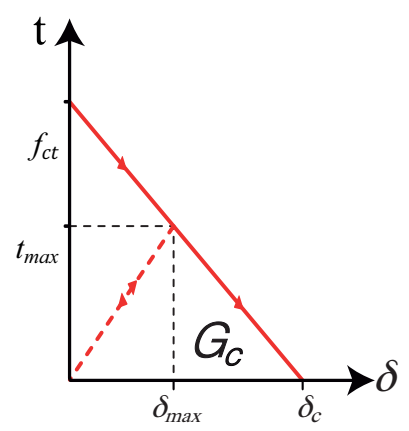

Figure 7: Representation of the linear cohesive law.

the nodes of the finite element mesh which are located on the upper (respectively lower) boundary are forced to move at a constant velocity $V_{0 y}=V_{0}$ (respectively $V_{0 y}=-V_{0}$ ) with $V_{0 x}=0$ :

$$
V_{0}=\dot{\varepsilon} \frac{h}{2}
$$

where $h$ is the height of the studied specimen. To avoid stress wave propagation and an early fracture near the boundaries, all the nodes of the finite element mesh are prescribed an initial velocity in accordance to their vertical position $y[42]$ as illustrated in Figure 8:

$$
V_{y}(y)=\frac{2 V_{0}}{h} y
$$
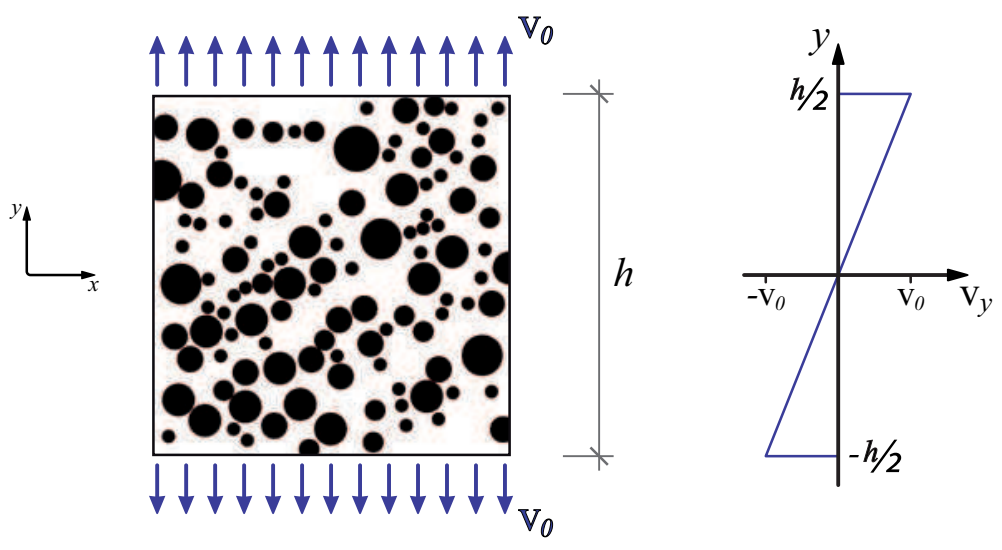

Figure 8: Velocity initial condition

No initial transversal velocity is applied on the specimen $\left(V_{x}=0\right)$. This means that due to Poisson effect, the stress state is not fully uniaxial (note that this is also the case in real experiments). Indeed, it is well known that the rate effect in compression is mostly due to a structural confinement and the main aim of this tension test is to try to understand if we have the same origin for the experimental tensile rate effect.

The finite element code used for this study is based on a Newmark explicit time integration scheme. This scheme is conditionally stable so that the time step has to be smaller than a critical value usually computed as follows (Courant-Friedrichs-Lewy condition): 


$$
\Delta t_{\text {crit }}=\min _{e=1}^{N_{e}}\left(\frac{l_{e}}{c}\right)
$$

where $c$ is the pressure wave speed in the phase of the material of the element $e$ and $l_{e}$ is the size of this element (in 2D the radius of the larger inner circle). The stable time step has to be chosen equal to the smallest value of the critical time step - over all the elements - multiplied by a security coefficient $\alpha$ (equal to 0.1 in our simulation). For example, for the meshes shown on Figure 5, one obtains for the computational time step $\Delta t=1.83810^{-9} s$ and $7.88210^{-10} s$ for the meshes A and $\mathrm{D}$ respectively.

To obtain the stress-strain curves, we define the macroscopic stress as the boundary reaction force $F_{y}$ divided by the initial width of the specimen and the macroscopic strain as the displacement $U_{y}$ of the boundary divided by the initial height $h$ of the specimen.

\subsection{Material parameters and mesh objectivity}

As shown in section 2 our numerical model is based on three phases: the mortar paste, the aggregates and an ITZ. For these phases we have to identify the elastic and rupture parameters of equation 5 . In the present work, we used the parameters given in Table 2.

Table 2: Material properties used for the mesh sensitivity study

\begin{tabular}{l|c|c|c|} 
& Aggregate & Mortar paste & ITZ \\
\hline Density $-\rho\left(\mathrm{kg} / \mathrm{m}^{3}\right)$ & 2700 & 2200 & - \\
\hline Young's modulus $-\mathrm{E}(\mathrm{GPa})$ & 75 & 25 & - \\
\hline Poisson's ratio $-\nu$ & 0.2 & 0.2 & - \\
\hline Fracture Energy $-G_{c}\left(\mathrm{~J} / \mathrm{m}^{2}\right)$ & 60 & 50 & 30 \\
\hline Tensile Strength $-f_{c t}(\mathrm{MPa})$ & 10 & 4 & $2.4^{1}$ \\
\hline Cohesive zone length $-l_{z}(\mathrm{~mm})$ & 41 & 72 & - \\
\hline
\end{tabular}

The relationship between the cohesive element law and $G_{c}$ introduces a length scale - called the cohesive zone length $l_{z}$ - into the material description. Rice and Palmer [43] calculated this length for linear elastic fracture mechanics in Mode I plane strain crack loading:

$$
l_{z}=\frac{9}{32} \frac{\pi E G_{c}}{\left(1-\nu^{2}\right) f_{c t}^{2}}
$$

This length has an important influence around the crack tip in numerical simulations. Typically one assumes that for mesh independency, the cohesive zone length has to be smaller than the specimen size and should contain at least three to four finite elements. For the material parameters of Table 2, the smallest and more constraining (or penalizing) cohesive zone length is of the order of $40 \mathrm{~mm}$ for the aggregates (see Table 3). It is important to notice that the definition of $l_{z}$ is not clear for the ITZ. Indeed, in our representation the ITZ is not meshed (null thickness) with the consequence that the Young modulus is not known in this region. Nevertheless, based on Equation 9 and the Mode I

\footnotetext{
${ }^{1}$ Contrary to [22] this value is estimated from $G_{c}$ of the ITZ with $\delta_{c}$ equal to the value obtained for the mortar. With this assumption one obtains a $f_{c t}$ smaller in the ITZ than in the mortar, which is commonly accepted for a classical concrete
} 
assumption, all the meshes of Figure 5 should give the same results due to an average element size lower than $1 \mathrm{~mm}$. In a previous work (Gatuingt et al. [44]) with other parameters for the aggregates, the cohesive zone length was equal to $4 \mathrm{~mm}$ and we showed that the mesh A was too coarse in this case.

Table 3: Cohesive length zone obtained with material properties of Table 2

\begin{tabular}{l|c|c|c|} 
& Aggregate & Mortar paste & ITZ \\
\hline Cohesive zone length $-l_{z}(\mathrm{~mm})$ & 40 & 72 & - \\
\hline
\end{tabular}

This is confirmed in Figure 9 where the macroscopic tensile responses obtained for the different mesh refinements and two loading rates are shown. One can see on this figure that the differences between the four meshes are very slight. Only the mesh A gives something slightly different than the others for $\dot{\varepsilon}=10 / \mathrm{s}$. For this mesh, the element size $(\approx 1 \mathrm{~mm})$ is a little bit too coarse to have a good representation of the cement paste between two close aggregates (see Figure 5). From the second mesh size (mesh B) the results are converged for all the loading rates applied on the numerical specimen. This is confirmed with the Figure 10 where the crack path is plotted for all the meshes. One can see that in this case the crack path is not strongly mesh dependent. Indeed, it is well known that for a classical concrete (our study) the crack path in tension is mainly governed by the aggregate debonding caused by the low value of $f_{c t}$ for the ITZ. A numerical and an experimental study of the impact of the ITZ strength on the global strength are given in $[45,46]$ respectively.
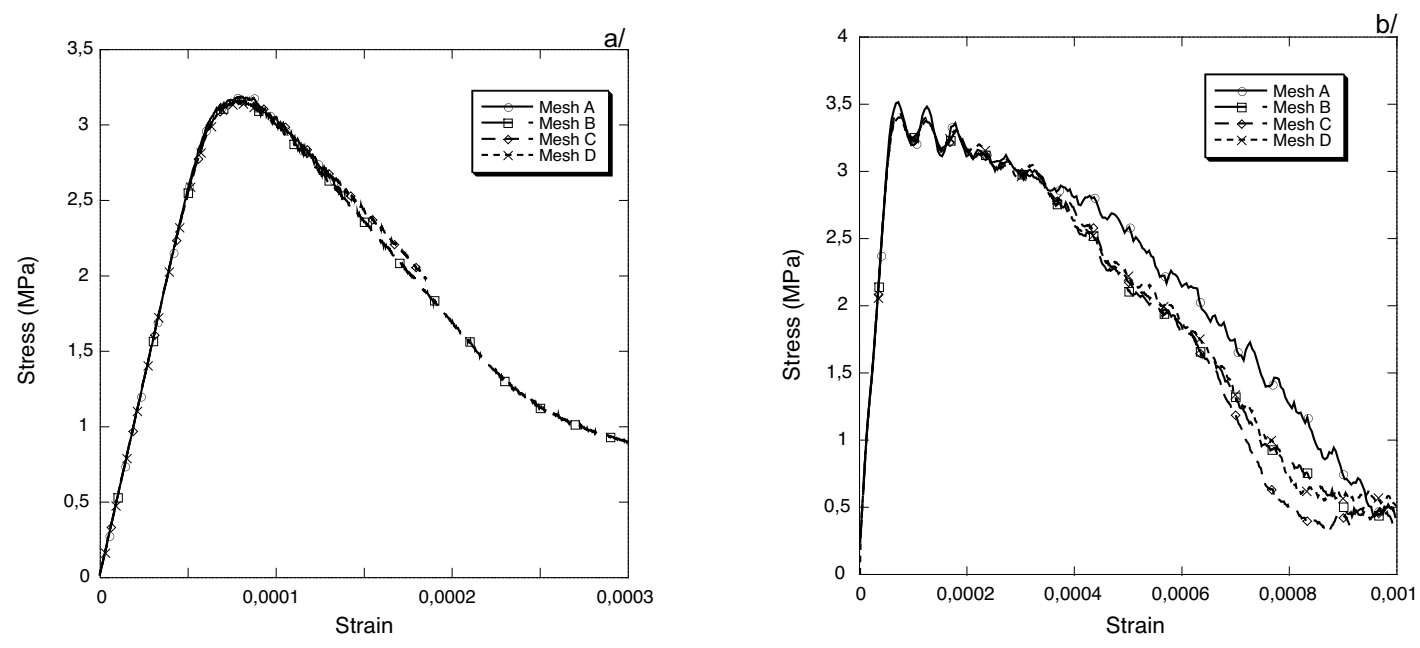

Figure 9: Influence of the mesh refinement on the stress-strain curves: a/ $\dot{\varepsilon}=0.1 / \mathrm{s} \mathrm{b} / \dot{\varepsilon}=10 / \mathrm{s}$

In the rest of the paper we choose for all the meso-structures studied a mesh refinement similar to the mesh B. This mesh size is small enough for the definition of $l_{z}$ and to describe the smallest aggregates and large enough to induce an acceptable CPU time for parametric studies.

\subsection{Influence of the specimen size}

In order to see the influence of the specimen size on our results, we generate a large sample in which we cut a smaller one in order to have the same aggregate/paste ratio and the same aggregate 
A
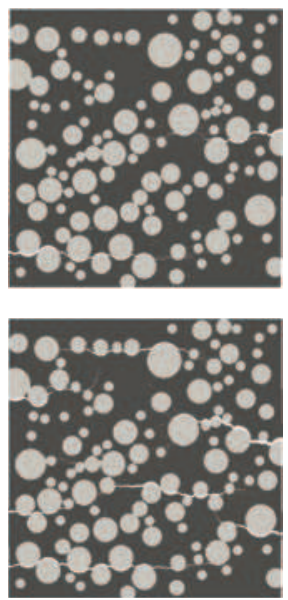

B
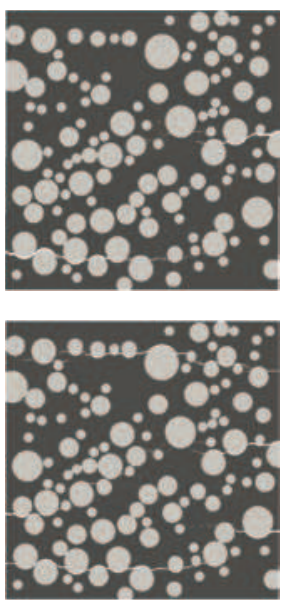

C
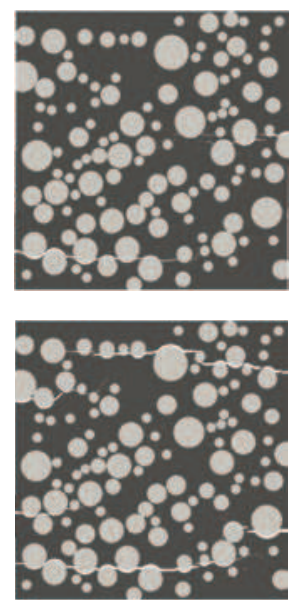

D
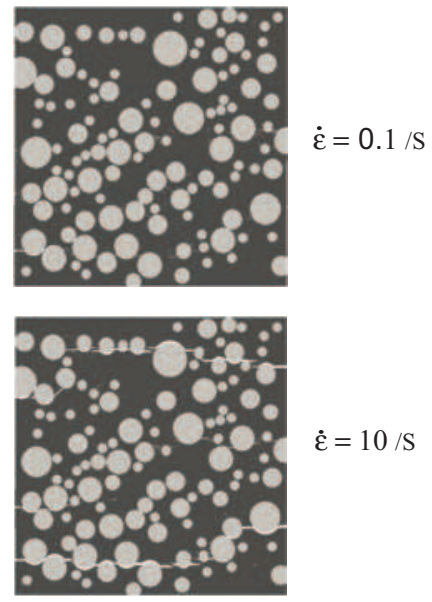

Figure 10: Influence of the mesh refinement on the crack path for two loading rates.
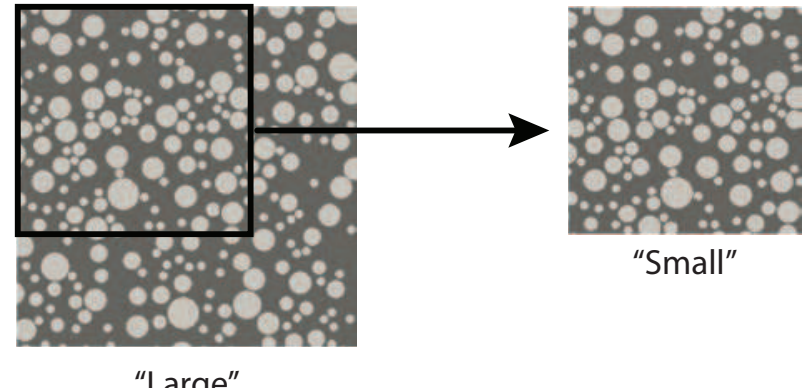

"Small"

"Large"

Figure 11: Large vs small size of the specimen

arrangement (see Figure 11). The large sample has a surface $S_{L}=0.15 \times 0.15 \mathrm{~cm}^{2}$ while for the small one $S_{S}=0.1 \times 0.1 \mathrm{~cm}^{2}$. The consequence is that we increase the width of the sample of $50 \%$ and the surface of $225 \%$.

Figure 12 and Figure 13 show the results obtained for two different loading rates $(\dot{\varepsilon}=1 / \mathrm{s}$ and $\dot{\varepsilon}=100 /$ s). We can notice that the crack path obtained is very similar for the two sample sizes. This result is confirmed with the macroscopic stress-strain responses of the specimens. Nevertheless we can observe that the peak strength is a little bit smaller for the large sample compared to the small one. This size effect in quasi-brittle materials such as concrete is a well known phenomenon and there are a number of experimental and theoretical studies (see for example [47, 48, 49]) which confirm its existence. Moreover in Figure 13, the post-peak response is clearly different for the two sample sizes. This result is not surprising because the post-peak response is more governed by the fracture energy. This is confirmed in Figure 14a where the evolution of the dissipated fracture energy (per unity in the sample depth) is plotted for different strain rates. As expected, for a larger sample we obtain a higher dissipated energy. If we assume an horizontal single crack, we can divide this energy by the width of the specimen and plot a normalized dissipated fracture energy (Figure 14b). In this figure we can see that the assumption of a single crack is not inaccurate for the lower strain rate $(\dot{\varepsilon}=1 / \mathrm{s})$ where a "single" crack appears (Figure 12). For higher strain rates $(\dot{\varepsilon}=100 /$ s), due to the multiple cracks this assumption is no longer true and the normalized dissipated fracture energy strongly depends on 

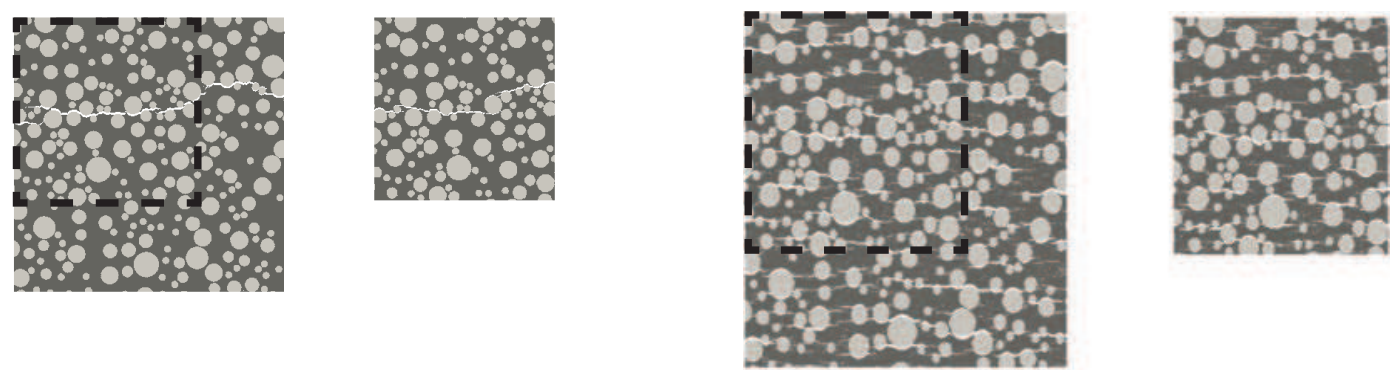

Figure 12: Influence of the specimen size on the fracture path: a/ $\dot{\varepsilon}=1 / \mathrm{s} \mathrm{b} / \dot{\varepsilon}=100 / \mathrm{s}$
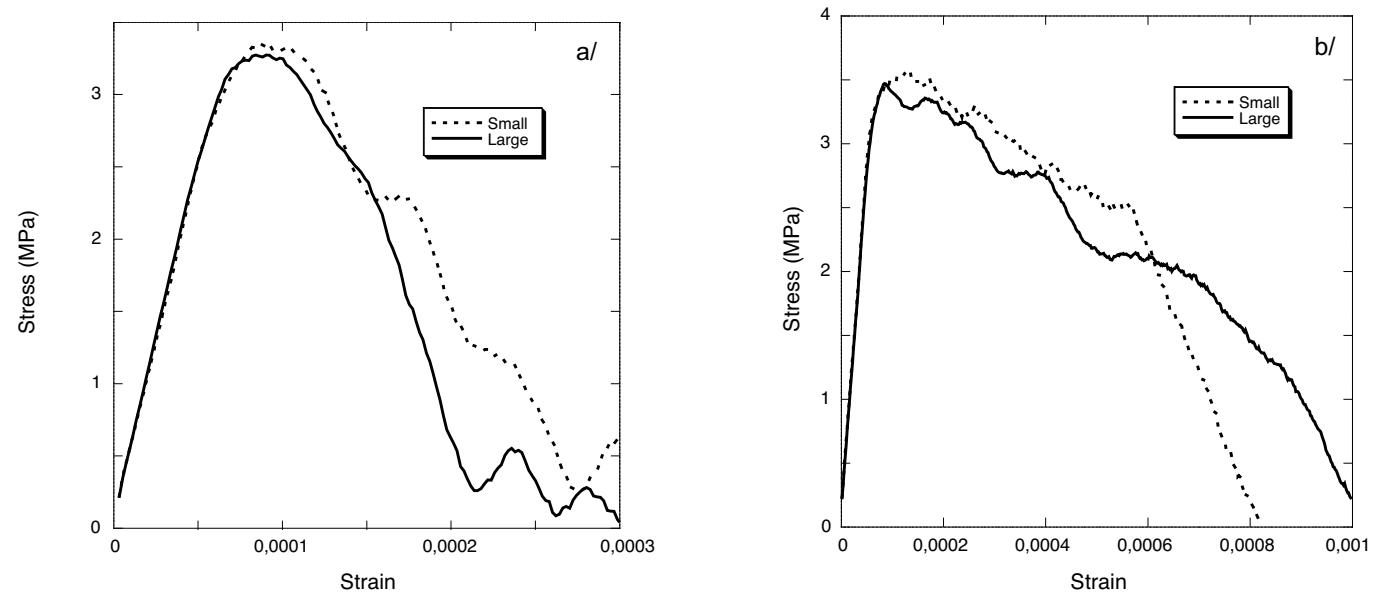

Figure 13: Influence of the specimen size on the stress-strain curves: $\mathrm{a} / \dot{\varepsilon}=1 / \mathrm{s} \mathrm{b} / \dot{\varepsilon}=10 / \mathrm{s}$

the specimen size. The larger the sample, the bigger is the Dynamic Increase Factor (DIF). In our case, we obtain a DIF equal to 8 for the smaller sample and equal to 10 for the larger one. We can conclude that in high loading rate regimes the numerical (and experimental) results are affected by this structural effect and it is not easy to properly quantify the true fracture energy values (the size of the sample is important).

To choose the sample we have to used, we can notice that the size of the numerical "small" specimen is bigger than the experimental one (cylinder with a diameter of $74 \mathrm{~mm}$ [14]) in which case a smaller DIF value should be obtained. We recall that the numerical DIF is 8 for the small sample whereas the experimental DIF is 12 . As the aim of this work is not to study how we can reproduce the size effect with our model (even if the global trend seems adequate) we decided to keep the smaller size of the specimen for the subsequent sections.

\section{Role of the meso-structure on the dynamic tensile response}

The meso-structures used in this part are those presented in Figure 4 with a mesh refinement similar to the mesh $\mathrm{B}$ in order to have a quasi-independence of the chosen mesh on the numerical results.

As previously mentioned, the numerical model does not contain any random field to represent the 

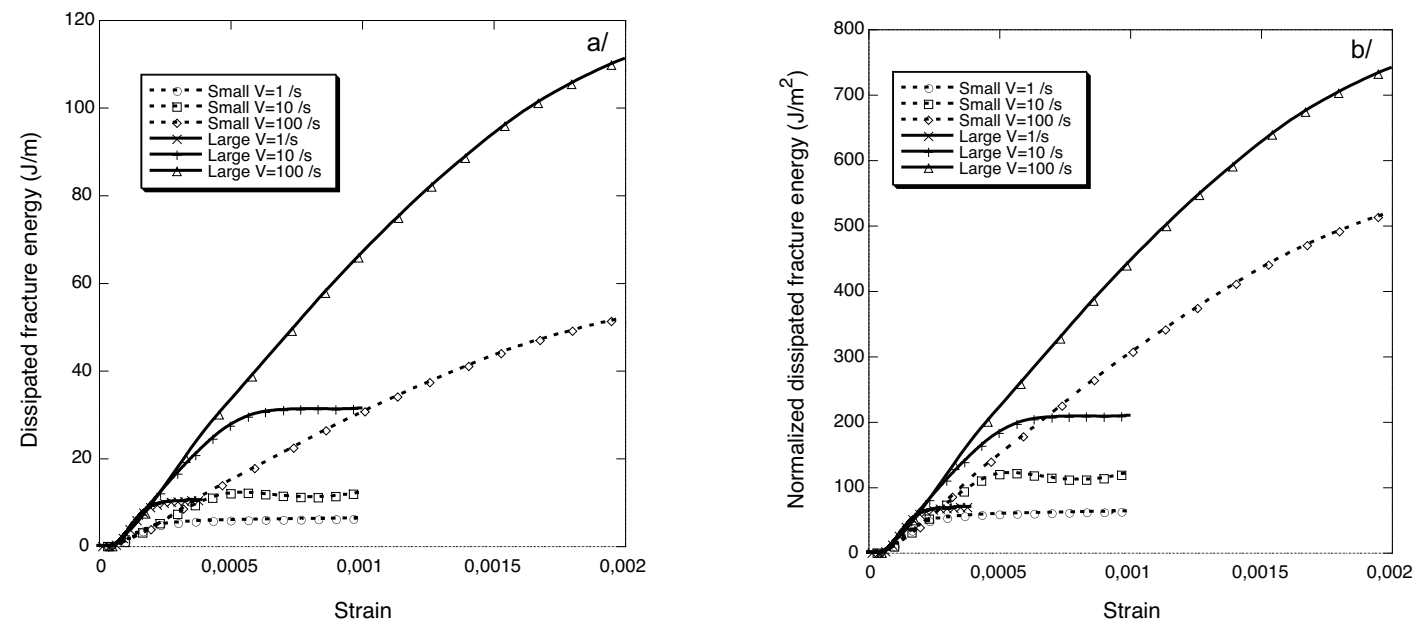

Figure 14: Influence of the specimen size on the dissipated fracture energy: a/ total energy, b/ normalized energy

scattering often observed on the macroscopic response of concrete. This scattering can be important in experimental tests for the same initial concrete mix but tested on several specimens. The main differences are then due to the different aggregate arrangements and to the macro-porosity distribution. In this section, we study only the influence of spatial distribution of aggregates and not the role of the macro-porosity. This porosity has probably a great influence on the crack initiation and ultimately on the crack path but in order to clearly separate the influence of aggregates, it will be omitted in our simulations.

The results of the strain-stress curves obtained for our five numerical concrete specimens in tension for several strain rates are presented in Figure 15. One can see on this figure that the microstructure has a slight influence (less than $4 \%$ ) on the peak strength value of our concrete. The macroscopic tensile strength is mainly governed in our case by the ITZ strength and not by the meso-structure. This can be best explained by examining the failure process in quasi-static for which we can observe a gradual transition from diffuse micro-cracking to strain localization and finally to a macroscopic crack. Figure 16 shows this evolution to a unique macroscopic crack for $\dot{\varepsilon}=0.1 / \mathrm{s}$. In the upper row of Figure 16, which was obtained at the peak stress just before strain localization, one can remark that for the five meso-structures, the micro-cracks are diffuse and that their numbers are almost independent of the aggregates spatial distribution. This explains the slight influence on the peak strength value observed at the macroscopic scale. Conversely, on the lower row of Figure 16, which is extracted from the softening part, we notice that the crack path is strongly dependent on the mesostructure. This is why one obtains a stronger difference $(50 \%)$ on the stress value for $\varepsilon=3.10^{-4}$ at the end of the loading for $\dot{\varepsilon}=0.1 / \mathrm{s}$.

Even if the failure process is not really the same for high strain rates (see next section), one can observe on Figure 15 that the meso-structure affects only the post-peak macroscopic response of our numerical concrete. It is interesting to notice that the influence of the meso-structure does not play the same role for all loading rates. For example the meso-structure 2 has the smallest strain at complete failure of the specimen for $\dot{\varepsilon}=10 / \mathrm{s}$ but this is not the case for the other loading rates. Therefore, while heterogeneities play in general an important role, no conclusion can be made on how their influence can be extrapolated from one loading rate to another. 

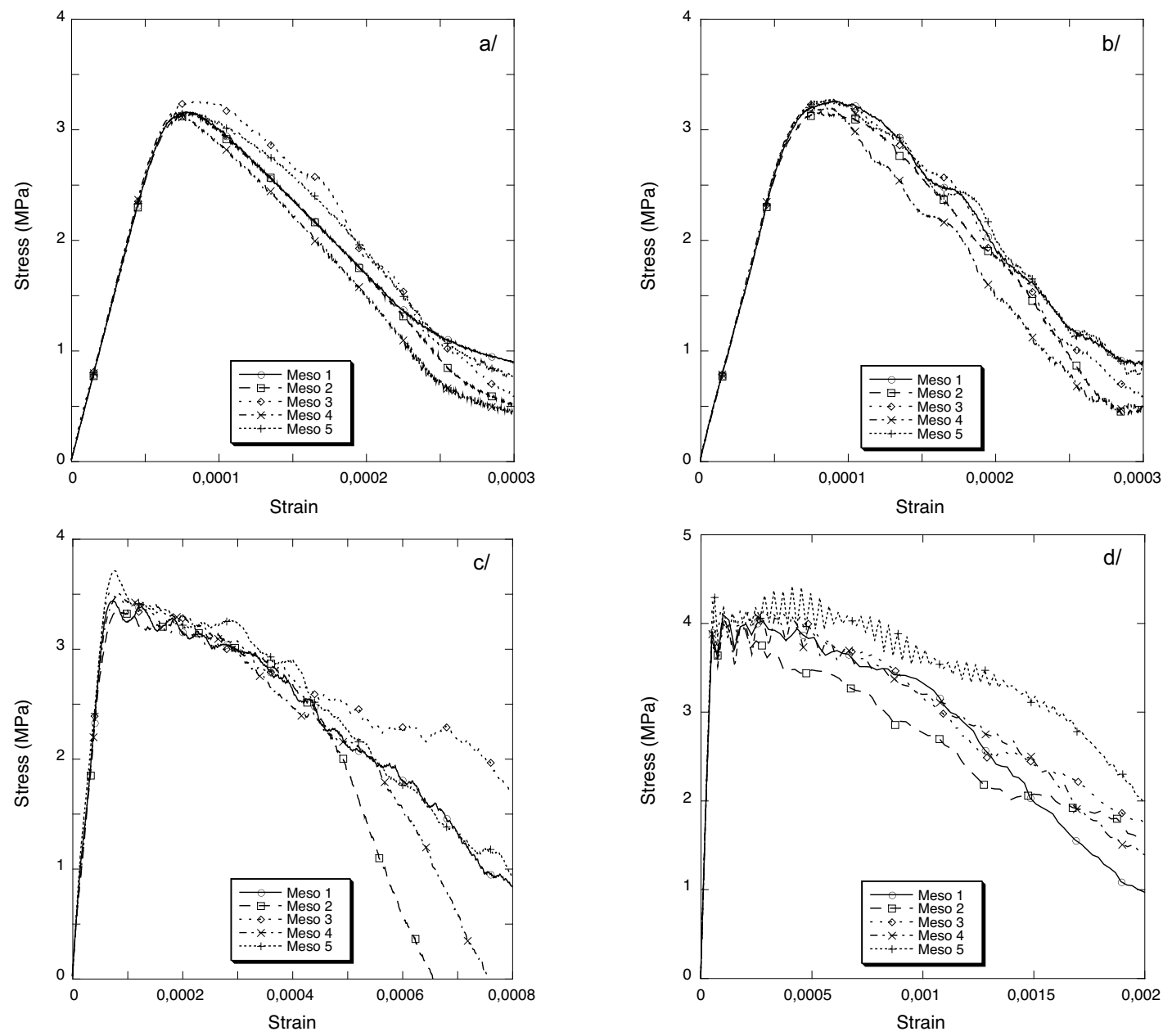

Figure 15: Influence of the meso-structure on the stress-strain curves for different strain rates: a/ $\dot{\varepsilon}$ $=0.1 / \mathrm{s}, \mathrm{b} / \dot{\varepsilon}=1 / \mathrm{s}, \mathrm{c} / \dot{\varepsilon}=10 / \mathrm{s}, \mathrm{d} / \dot{\varepsilon}=100 / \mathrm{s}$

\section{Loading rate effect and dissipation}

Experimental results on dynamic tension tests show a high rate sensitivity of tensile strength [50, 13]. Figure 17 presents results obtained in literature. If one considers these experimental results as a material behavior at the macro scale, this leads to models which are difficult to relate to physical mechanisms that occur during failure.

Nevertheless one can see from Figure 17 that two distinct modes appear with regards to the increase of the tensile strength with respect to the strain rate. In the first mode $-\dot{\varepsilon}<1 / \mathrm{s}-$ the dynamic resistance increase is probably due to the presence of water in the material. The free water in the micro-pores is assumed to exhibit the so-called Stefan-effect causing a strengthening effect in concrete with increasing loading rate [51]. This Stefan-effect is the phenomenon that occurs when a viscous liquid is trapped between two plates that are separated quickly, causing a reaction force on the plates that is proportional to the velocity of separation. Cadoni et al. [52] give a different explanation for the influence of the moisture content. Their interpretation is based on the principle of wave propagation in concrete. When a pore is not filled with water, it will locally reflect the incoming stress wave. The multiple reflections of all pores together can cause a considerable increase 


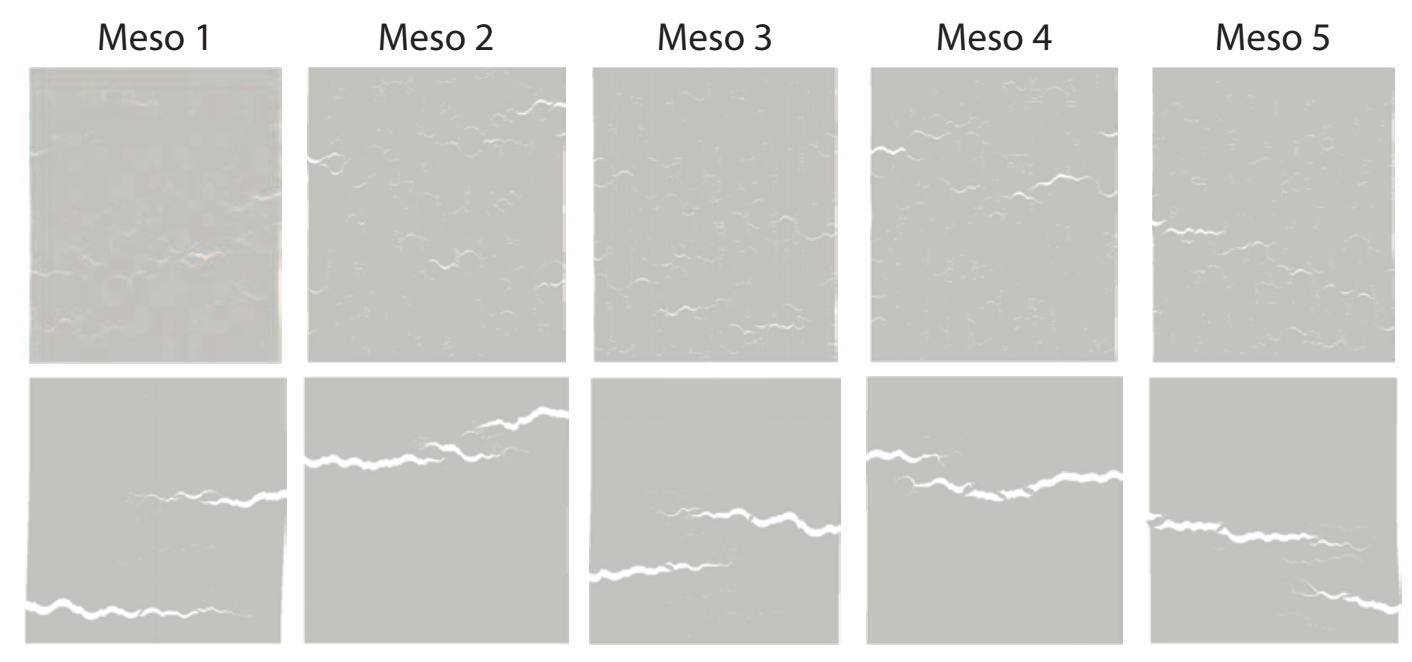

Figure 16: Influence of the meso-structure on the crack path for different meso-structures at $\dot{\varepsilon}=0.1$ /s: upper row at $\varepsilon=7.10^{-5}$ for $\approx$ the peak stress (disp. $\left.\times 2000\right)$, lower row at $\varepsilon=3.10^{-4}$ (disp. $\times$ 100)

in stress. When a stress wave meets a pore that is filled with liquid, the reflected stress is not big enough to locally provoke the damage of the material. Therefore the wet concrete will exhibit a more pronounced rate effect than the dry concrete. This interpretation only gives an explanation of the difference between wet and dry concrete and does not explain the increase in strength between static and dynamic loading. At a larger scale (the constitutive level), Ozbolt et al. [53] believe that the rate dependency consists of two parts: a rate dependency related to the formation of the micro-cracks, and a rate dependency due to the creep of concrete between the micro-cracks. Then, the influence of inertia forces on the rate effect is not part of the constitutive law, however, this effect is automatically accounted for in dynamic analysis in which the constitutive law interacts with inertia forces.

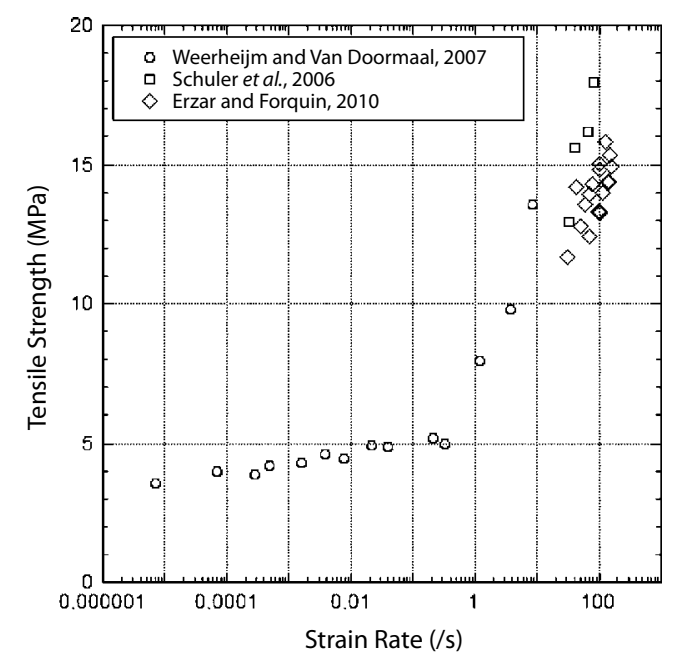

Figure 17: Experimental rate effect in tension (from [13])

In this work we will attempt to show if micro-inertia effects in the fracture process zone are sufficient to explain the rate dependency of concrete and the high fracture energy dissipation in a 
high rate regime. That is why the model used for the cohesive traction law of Figure 7 is not rate dependent. Moreover the concrete moisture content is usually assumed not to be dominant in the high strain rate regime. Thus, we will not consider it in this study.
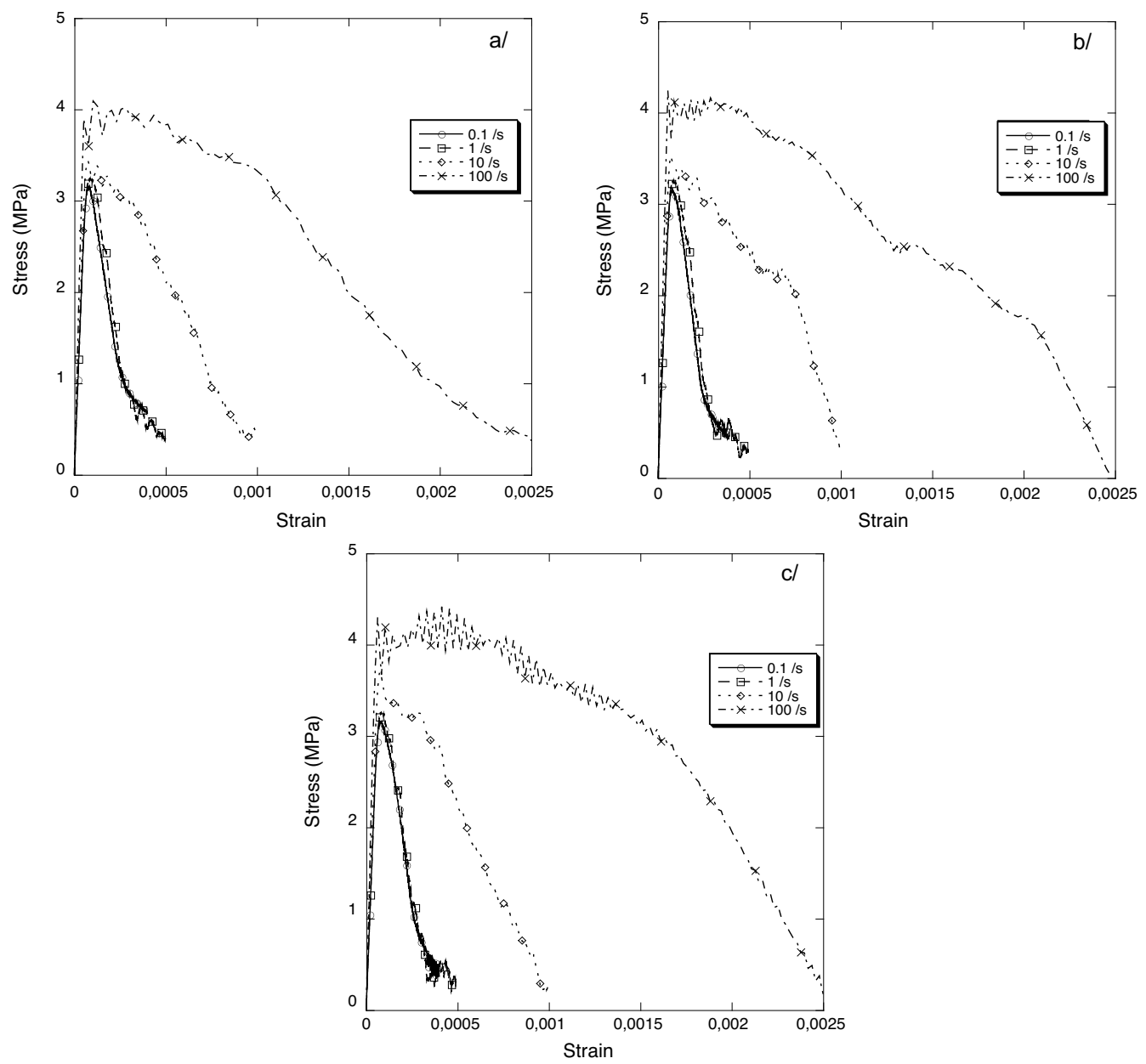

Figure 18: Numerical rate effect in tension for three meso-structures: a/ Meso 1, b/ Meso 3, c/ Meso 5

Figure 18 shows the numerical rate effect in tension obtained for three meso-structures with our assumptions. One can see on this figure that the computed increase with strain rate is slight concerning the tensile strength. We obtain here a dynamic increase factor - equal to the ratio of the static versus the dynamic strengths - of 1.3 for $\dot{\varepsilon}=100 / \mathrm{s}$ while it is equal to approximately 3 in the experiments. This result shows that the assumption of no rate effect in the cohesive traction law is not realistic. The micro-inertia effects in the fracture process zone are not sufficient to explain the rate dependency of concrete in tension even at the highest loading rate velocities. One has to take into account a rate dependency at the material level, for example by linking the cohesive strength $f_{c t}$ to the strain rate.

Figure 19 depicts the evolution of the dissipated fracture energy as function of the macroscopic strain of the specimen for different loading rates and heterogeneities. One can see on this figure that, as already observed in Figure 18, the dissipated fracture energy strongly depends on the loading rate even with a rate independent local fracture energy (see Equation 5 and Figure 7). Here we obtain a ratio $G_{f(d y n)} / G_{f(s t a t)}$ equal to approximately 8 - depending on the meso-structure - for $\dot{\varepsilon}=100 / \mathrm{s}$. In the experimental data (see Table 1), with a Young's modulus of the concrete approximately equal 

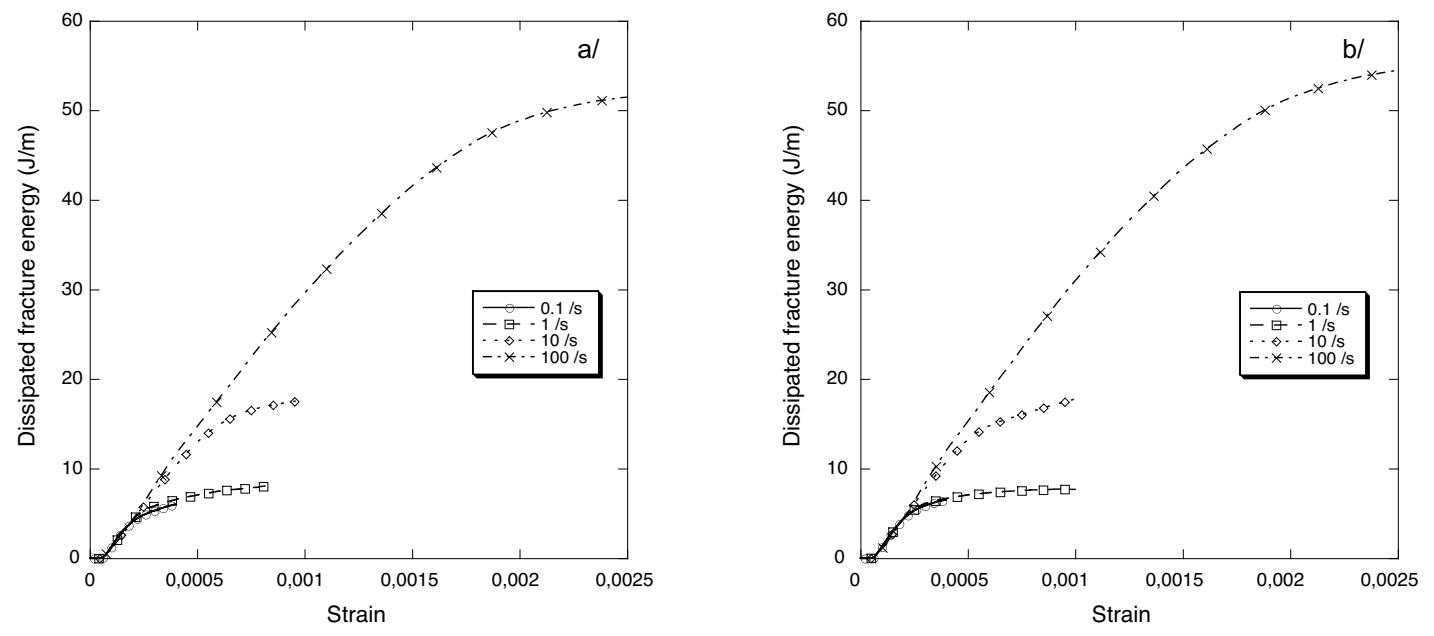

Figure 19: Influence of the meso-structure on the dissipated fracture energy for different strain rates: a/ Meso 1, b/ Meso 5

to $40 \mathrm{GPa}$ we obtain a ratio of 12 for $\dot{\varepsilon}=40 / \mathrm{s}$ (compared to quasi-statics). We note that even if the dynamic increase factor for the tensile strength is not large enough, it is less the case for the dissipated fracture energy. Moreover, and as expected, the dissipated fracture energy depends on the meso-structure (Figure 19a vs Figure 19b) due to the differences observed in Figure 15 on the post-peak curves.

b/

a/

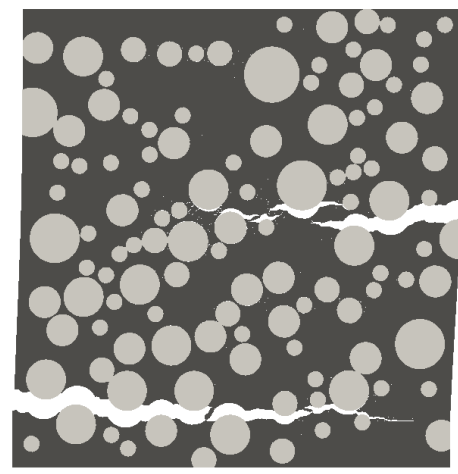

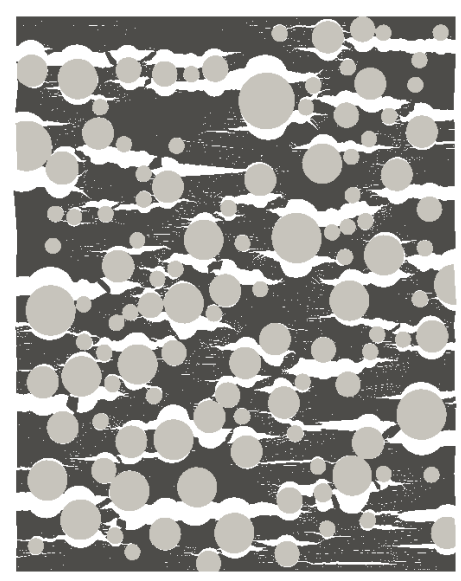

Figure 20: Influence of the loading rate on the final cracking for the meso-structure Meso 1 (disp. $\times$ 100): a/ $\dot{\varepsilon}=0.1 / \mathrm{s}, \mathrm{b} / \dot{\varepsilon}=100 / \mathrm{s}$

According to the structural effect hypothesis, the explanation of higher dissipated fracture energy for high loading rates resides in a more diffuse micro-cracking. In the higher loading rate regime, the initiation of the micro-cracks are similar to that observed for a slow regime (see Figure 16 upper row) around the peak stress of the macroscopic strain-stress curve, but multiple cracks appear in the softening regime. This effect can be seen on Figure 20 where the final aspect of the concrete specimen 
based on the meso-structure Meso 1 are compared for low and high loading rates. This behavior only explains that the differences between low and high loading rates are not important for the peak stress but only for the total dissipated fracture energy, which is in contradiction with experimental observations. Moreover in Figure 20b/ we can notice that, contrary to experimental observations, we do not have aggregates failure at high rates. The origin of this phenomenon is not clear (several assumptions could be removed to better understand this, including, spherical shape of the aggregates, rate independency of the ITZ, choice of the material parameters).

On the contrary, the material view point sustains that the increase of toughness could be an effect of internal material "hardening". One can argue that this mechanism should be related to the chosen modeling scale. i.e. when considering a large modeling scale (macroscale), the toughness parameter of the cohesive approach could be a function of the loading rate, as the mesh size cannot be small enough to capture all micro-cracking mechanisms. Whereas, decreasing the scale should entail a rate independent toughness parameter. This part is not really clear on Figure 21, which shows the evolution of the total fracture energy dissipated for mesh B and mesh D of the meso-structure called Meso 1. Indeed, for the mesh $\mathrm{D}$ the average size of the elements is $0.25 \mathrm{~mm}$ and one observes a small increase in the dissipated fracture energy in comparison with the mesh B $(0.5 \mathrm{~mm})$ with no real effect on the peak strength. Moreover with the mesh $\mathrm{D}$, the finite element size is close to the average size of the entrained air bubbles (micro-pores) [54], the larger heterogeneities at this scale. So it could be pertinent to keep this scale and to incorporate a material rate effect in the cohesive traction law to represent the Stefan effect [51] at the paste level.

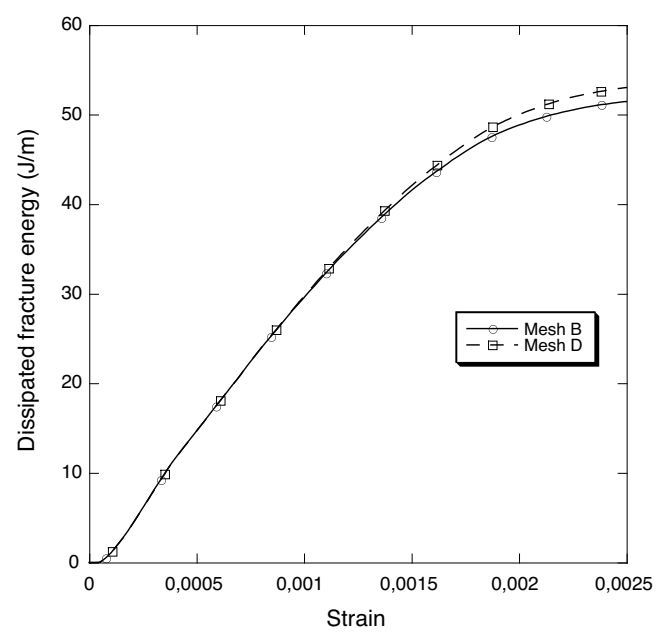

Figure 21: Influence of the mesh refinement on the dissipated fracture energy for $\dot{\varepsilon}=100 / \mathrm{s}$

Snozzi et a. [22] have shown that choosing a rate dependent cohesive traction law - where the cohesive strength is a material constant value, while the critical opening displacement is a function of the crack opening rate - does not involve a difference in the peak strength values and dissipated fracture energy in comparison with a rate-independent law. They attribute this to a size effect due to the physical dimension of the RVE. Indeed, for the concrete phases parameters and for the loading rates considered in this paper, we observe that the numerical results are more controlled by the strength parameters (strength controlled regime) than by the toughness.

To improve our simulations and the representativeness of our numerical concrete, the challenge will be to find a rate dependent cohesive traction law (at least for the $f_{c t}$ value) that will not increase 
too much the total dissipated fracture energy and the material ductility . One can for example use a function closed to the one proposed by Bažant and Li [55]. But an open question remains. Should one use a rate dependent function for only the ITZ, mortar, or aggregates or for all the parts of the meso-structure? This point will be difficult to answer without some specific experiments on the different constituents of a real concrete.

\section{Conclusion}

In this paper we proposed a meso-scopic model for the analysis of dynamic tensile failure of concrete. This model is based on a 2D finite element description with cohesive capability of a mix of aggregates larger than $4 \mathrm{~mm}$ in a mortar paste matrix. The distribution of the coarse aggregates is assumed to follow a realistic aggregates size distribution. Five meso-structures are generated with this distribution. The influence of the heterogeneous meso-structure of concrete and the loading rate on the tensile response and the dissipated fracture energy are studied. With our specimen size we observe a small impact of the aggregates arrangement on the tensile strength. This is because for our model parameters, the size of our specimen is large enough for a strength analysis and thus we can consider that a "material" response (independent of aggregates arrangement) is properly captured. This is of course based on the strong assumption of a perfect mix with no macro-porosity. Nevertheless when the post-peak response and the dissipated fracture energy are considered, we show that the mesostructure has an influence (as well as the sample size) and then the "homogeneous" regime has not been obtained. It is important to notice that the definition of homogeneity depends not only on the material description but also on the phenomenon observed.

The second main interest of the paper is the study of the dynamic loading rate effects on the tensile strength and on the dissipated fracture energy with our approach. The cohesive law used is independent of the local or global strain rate to investigate if the experimentally observed dynamic increase factor is due to a material effect or a structural (inertial) effect. With regards to tensile strength, the numerical results exhibit a small rate effect that is not coherent with the experiments. Interestingly, for the dissipated energy the numerical results are close to the experimental ones. This implies that the tensile strength increase is probably mostly due to a material effect (moisture, viscoelasticity, ...) while the dissipated fracture energy observed in the post-peak part is more due to the increase of the number of micro-cracks with the loading rate. With adding a small rate dependency in the cohesive law could permit to have a realistic virtual material to test the influence of other experimental configurations.

\section{Acknowledgments}

This material is based on the work supported by the Swiss National Foundation under Grant no. 200021 122046/1. We want to thank the ENAC school at EPFL for supporting the sabbatical visit of the first author.

\section{References}

[1] Ottosen N. Constitutive model for short-time loading of concrete. Journal of the Engineering Mechanics Division-ASCE 1979; 105(1):127-141. 
[2] Sluys L. Wave propagation, localisation and dispersion in softening solids. Doct. Dissertation, Delft University of Technologie-Delft, 1992.

[3] Dubé J, Pijaudier-Cabot G, La Borderie C. Rate dependent damage model for concrete in dynamics. Journal of Engineering Mechanics-ASCE 1996; 122(10):939-947.

[4] Sercombe J, Ulm F, Toutlemonde F. Viscous hardening plasticity for concrete in high-rate dynamics. Journal of Engineering Mechanics-ASCE 1998; 124(9):1050-1057.

[5] Bažant Z, Caner F, Adley M, Akers S. Fracturing rate effect and creep in microplane model for dynamics. Journal of Engineering Mechanics-ASCE 2000; 126(9):962-970.

[6] Gatuingt F, Pijaudier-Cabot G. Coupled damage and plasticity modelling in transient dynamic analysis of concrete. Int. J. Numer. Anal. Meth. Geomec. 2002; 26:1-24.

[7] Hervé G, Gatuingt F, Ibrahimbegovic A. On numerical implementation of a coupled rate dependent damage-plasticity constitutive model for concrete in application to high-rate dynamics. Engineering Computations 2005; 22(5-6):583-604.

[8] Pedersen R, Simone A, Sluys L. An analysis of dynamic fracture in concrete with a continuum visco-elastic visco-plastic damage model. Engineering Fracture Mechanics 2008; 75:3782-805.

[9] Gatuingt F, Desmorat R, Chambart M, Combescure D, Guilbaud D. Anisotropic 3d delay-damage model to stimulate concrete structures. Revue Européenne de mécanique numérique 2008; 17:74060 .

[10] Pontiroli C, Rouquand A, Mazars J. Predicting concrete behaviour from quasi-static loading to hypervelocity impact An overview of the PRM model. European Journal of Environmental and Civil Engineering 2010; 14(6-7):703-727.

[11] Desmorat R, Gatuingt F, Ragueneau F. Nonstandard thermodynamics framework for robust computations with induced anisotropic damage. International Journal of Damage Mechanics, 2010; 19:53-73.

[12] Weerheijm J, Vegt I, van Breugel K. The rate dependency of concrete in tension - New data for wet, normal and dry conditions. DYMAT 2009: 9th Inter. Conf. on the Mechanical and Physical Behaviour of Material under Dynamic Loading, Vol. 1, 2009; 95-101.

[13] Erzar B, Forquin P. An Experimental Method to Determine the Tensile Strength of Concrete at High Rates of Strain. Experimental Mechanics 2010; 50(7):941-955.

[14] Weerheijm J, Vegt I, van Breugel K. Research developments and experimental data on dynamic concrete behaviour. Conference on Advances in Construction Materials, 2007; 765-773.

[15] Kormeling H, Reinhardt H. Strain rate effects on steel fibre concrete in uniaxial tension. Int. Journal of Cement Composites and Lightweight Concrete 1987; 9(4):197-204.

[16] Oh B. Fracture behavior of concrete under high rates of loading. Int. J. Eng. Fract. Mech. 1990; 35(1/2/3):327-332.

[17] Rossi P, van Mier J, Toutlemonde F, Maou C Fand Boulay. Effect of loading rate on the strength of concrete subjected to uniaxial tension. Materials and Structures 1994; 27:260-264. 
[18] van Doormaal J, Weerheijm J, Sluys L. Experimental and numerical determination of the dynamic fracture energy of concrete. Journal de physique IV 1994; 4(C8):501-506.

[19] Vegt I, van Breugel K, Weerheijm J. Failure mechanisms of concrete under impact loading. Fracture Mechanics of Concrete and Concrete Structures, FraMCoS-6, vol. 1, Carpinteri, A and Gambarova, PG and Ferro, G and Plizzari, GA (ed.), 2007; 579-587.

[20] Chambart M. Endommagement anisotrope et comportement dynamique des structures en béton armé jusqu'à la ruine. PhD Thesis, ENS Cachan, France 2009.

[21] Levy S, Molinari JF, Vicari I, Davison AC. Dynamic fragmentation of a ring: Predictable fragment mass distributions. Phys. Rev. E 2010; 82(6, Part 2).

[22] Snozzi L, Caballero A, Molinari J. Influence of the meso-structure in dynamic fracture simulation of concrete under tensile loading. Cement and Concrete Research 2011; 41(11):1130-1142.

[23] Wittmann FH. Structure of concrete with respect to crack formation. Fracture Mechanics of Concrete, Elsevier Science Publishers 1983; :43-74.

[24] Schlangen E, van Mier JGM. Simple lattice model for numerical simulation of fracture of concrete materials and structures. Materials and Structures 1992; 25(9):534-542.

[25] Bolander Jr JE, Saito S. Fracture analysis using spring networks with random geometry. Engineering Fracture Mechanics 1998; 61(5-6):569-591.

[26] Kozicki J, Tejchman J. Effect of aggregate structure on fracture process in concrete using 2d lattice model. Archives of Mechanics 2007; 59:365-384.

[27] Grassl P, Jirásek M. Meso-scale approach to modelling the fracture process zone of concrete subjected to uniaxial tension. International Journal of Solids and Structures 2010; 47(7-8):957968.

[28] Cusatis G. Strain-rate effects on concrete behavior. International Journal of Impact Engineering 2011; 38(4):162-170.

[29] Roelfstra P, Sadouki H, Wittmann F. Le béton numerique. Materials $\& 3$ Structures - RILEM 1985; 18:309?317.

[30] Stankowski T. Numerical simulation of progressive failure in particle composites. PhD Thesis, University of Colorado, USA 1990.

[31] Lopez C. Microstructural analysis of concrete fracture using interface elements. application to various concretes. PhD Thesis, Universitat Politècnica de Catalunya, Spain 1999.

[32] Caballero A. 3d meso-mechanical numerical analysis of concrete using interface elements. PhD Thesis, Universitat Politècnica de Catalunya, Spain 2005.

[33] Carol I, Lopez C, Roa O. Micromechanical analysis of quasi-brittle materials using fracturebased interface elements. International Journal for numerical methods in enginnering 2001; 52(12):193-215. 
[34] EN 933-1. Tests for geometrical properties of aggregates - Part 1 : determination of particle size distribution - Sieving method.

[35] N'Guyen T, Lawrence C, La Borderie C, Nahas G. A mesoscopic approach for a better understanding of the transition from diffuse damage to localized damage. European Journal of Environmental and Civil Engineering 2010; 14:751-776.

[36] Langer L, Carter W, Fuller E. The ppm2oof manual. Technical Report, NIST 2009.

[37] Hillerborg A, Modéer E, Petersson P. Analysis of crack formation and crack growth in concrete by means of fracture mechanics and finite elements. Cement and Concrete Research 1976; 6(6):773781.

[38] Camacho G, Ortiz M. Computational modelling of impact damage in brittle materials. International Journal of Solids and Structures 1996; 33(20-22):2899-2938.

[39] Dugdale D. Yielding of steel sheets containing slits. Journal of the Mechanics and Physics of Solids 1960; 8:100-108.

[40] Barenblatt G. The mathematical theory of equilibrium of cracks in brittle fracture. Advances in Applied Mechanics 1962; 7:55-129.

[41] Ruiz G, Pandolfi A, Ortiz M. Three-dimensional cohesive modeling of dynamic mixed-mode fracture. Int. Journal for Numerical Methods in Engineering 2001; 52:97-120.

[42] Miller O, Freund L, Needleman A. Modeling and simulation of dynamic fragmentation in brittle materials. International Journal of Fracture 1999; 96(2):101-125.

[43] Palmer A, Rice J. The growth of slip surfaces in the progressive failure of over-consolidated clay. Proceedings of the Royal Society of London, Series A 1973; 332:527-548.

[44] Gatuingt F, Snozzi L, Molinari J. Influence of the meso-structure in numerical simulation of dynamic tensile fracture of concrete. International Conference on Computational Modeling of Fracture and Failure of Materials and Structures, CFRAC 2011., 2007.

[45] Pedersen R, Simone A, Stroeven M, Sluys L. Mesoscopic modelling of concrete under impact. 6th International Conference on Fracture Mechanics of Concrete and Concrete Structures - FRAMCOS VI, 2007; 571-578.

[46] Rocco C, Elices M. Effect of aggregate shape on the mechanical properties of a simple concrete. Engineering Fracture Mechanics 2009; 76:286-298.

[47] Reinhardt H. Similitude of brittle fracture of structural concrete. IABSE Colloquium on Advances in Reinforced Concrete, Delft, 1981; 175-184.

[48] Bažant Z. Size effect in blunt fracture: Concrete, rock, metal. Journal of Engineering Mechanics, $A S C E$ 1984; 110:518-535.

[49] Ožbolt J, Eligehausen R, Petrangeli M. The size effect in concrete structures. Size Effect In Concrete Structures, Mihashi H, Okamura H, Bažant Z (eds.). E \& FN Spon, London, 1994; $255-268$. 
[50] Vegt I, RR P, LJ S, Weerheijm J. Modelling of impact behaviour of concrete - an experimental approach. Computational Modelling of Concrete Structures - EURO-C 2006, 2006; 451-458.

[51] Rossi P, van Mier J, Boulay C, Le Maou F. The dynamic behaviour of concrete: influence of free water. Materials and Structures 1992; 25:509-514.

[52] Cadoni E, Labibes K, Albertini C, Berra M, Giangrasso M. Strain rate effect on the tensile behaviour of concrete at different relative humidity levels. Materials and Structures 2001; 34:2126.

[53] Ožbolt J, Li Y, Kožar I. Microplane model for concrete with relaxed kinematic constraint. International Journal of Solid and Structure 2001; 38:2683-2711.

[54] Mehta P. Concrete structure, properties, and materials. Prentice-Hall, 1986.

[55] Bažant Z, Li Y. Cohesive crack with rate-dependent opening and viscoelasticity: I. mathematical model and scaling. International Journal of Fracture 1997; 86:247-265. 